\title{
Changes in the Three-Dimensional Angular Vestibulo-Ocular Reflex following Intratympanic Gentamicin for Ménière's Disease
}

\author{
John P. Carey, ${ }^{1}$ Lloyd B. Minor, ${ }^{1-3}$ Grace C.Y. Peng, ${ }^{4,5}$ Charles C. Della Santina, ${ }^{1}$ \\ Phillip D. Cremer, ${ }^{6}$ and Thomas Haslwanter ${ }^{7}$ \\ ${ }^{1}$ Department of Otolaryngology-Head and Neck Surgery, Johns Hopkins University, Baltimore, MD 21287, USA \\ ${ }^{2}$ Department of Biomedical Engineering, Johns Hopkins University, Baltimore, MD 21205, USA \\ ${ }^{3}$ Department of Neuroscience, Johns Hopkins University, Baltimore, MD 21205, USA \\ ${ }^{4}$ Department of Neurology, Johns Hopkins University, Baltimore, MD 21287, USA \\ ${ }^{5}$ Department of Biomedical Engineering, Catholic University of America, Washington, DC 20064, USA \\ ${ }^{6}$ Eye and Ear Research Unit, Institute of Clinical Neurosciences, Royal Prince Alfred Hospital, Sydney, Australia \\ ${ }^{7}$ Department of Neurology, Zürich University Hospital, Zürich, Switzerland
}

Received: 19 June 2000; Accepted: 21 January 2002; Online publication: 26 March 2002

\begin{abstract}
The 3-dimensional angular vestibulo-ocular reflexes (AVOR) elicited by rapid rotary head thrusts were studied in 17 subjects with unilateral Ménière's disease before and 2-10 weeks after treatment with intratympanic gentamicin and in 13 subjects after surgical unilateral vestibular destruction (SUVD). Each head thrust was in the horizontal plane or in either diagonal plane of the vertical semicircular canals, so that each head thrust effectively stimulated only one pair of canals. The AVOR gains (eye velocity/head velocity during the $30 \mathrm{~ms}$ before peak head velocity) for the head thrusts exciting each individual canal were averaged and taken as a measure of the function of that canal. Prior to intratympanic gentamicin, gains for head thrusts that excited canals on the affected side were $0.91 \pm 0.20$ (horizontal canal, HC), $0.78 \pm 0.20$ (anterior canal, AC), and $0.83 \pm 0.10$ (posterior canal, PC). The asymmetries between
\end{abstract}

Correspondence to: Dr. John P. Carey - Department of Otolaryngology-Head and Neck Surgery • Johns Hopkins Outpatient Center

- Room 6253 - 601 North Caroline St. - Baltimore, MD 212870910. Telephone: (410) 955-3403; fax: (410) 614-7222;

email: jcarey@jhmi.edu these gain values and those for head thrusts that excited the contralateral canals were $<2 \%$. In contrast, caloric asymmetries averaged $40 \% \pm 32 \%$. Intratympanic gentamicin resulted in decreased gains attributable to each canal on the treated side: $0.40 \pm 0.12(\mathrm{HC}), 0.35 \pm 0.14(\mathrm{AC}), 0.31 \pm 0.14(\mathrm{PC})$ $(p<0.01)$. However, the gains attributable to contralateral canals dropped only slightly, resulting in marked asymmetries between gains for excitation of ipsilateral canals versus their contralateral mates: HC: $34 \% \pm 12 \%$, AC: $24 \% \pm 25 \%$, and PC: $42 \% \pm$ $13 \%$. There was no difference in the AVOR gain for excitation of the ipsilateral HC after gentamicin in patients who received a single intratympanic injection $(0.39 \pm 0.11, n=12)$ in comparison to those who received 2-3 injections $(0.42 \pm 0.15, n=5$, $p=0.7)$. Gain decreases attributed to the gentamicintreated $\mathrm{HC}$ and $\mathrm{AC}$ were not as severe as those observed after SUVD. This finding suggests that intratympanic gentamicin causes a partial vestibular lesion that may involve preservation of spontaneous discharge and/or rotational sensitivity of afferents.

Keywords: vestibulo-ocular reflex (VOR), Ménière's disease, vertigo, 3D eye movements, semicircular canals, hearing loss 


\section{INTRODUCTION}

When medical management fails to control intractable vertigo in unilateral Ménière's disease, options for treatment include labyrinthectomy, vestibular neurectomy, and intratympanic (middle ear) injection of gentamicin. Intratympanic aminoglycosides have long been known to be effective in controlling vertigo due to Ménière's disease. Schuknecht (using streptomycin) and Lange (using gentamicin) gave multiple intratympanic injections of these antibiotics each day until patients developed dysequilibrium or until caloric responses were abolished (Schuknecht 1957; Lange 1976, 1989, 1995a,b). Vertigo was controlled in most of these patients $(100 \%$ in Schuknecht's series; $88 \%$ in Lange's), but the rates of sensorineural hearing loss attributed to the aminoglycosides were unacceptably high ( $62 \%$ and $48 \%$, respectively). Subsequent reductions in the number and frequency of doses have resulted in control of vertigo in $70 \%-$ $90 \%$ of patients and a reduction in the incidence of sensorineural hearing loss (Beck and Schmidt 1978; Odkvist et al. 1984; Nedzelski et al. 1992, 1993; Toth and Parnes 1995; Murofushi et al. 1997; Hirsch and Kamerer 1997; Rauch and Oas 1997; Minor 1999; Silverstein et al. 1999; Atlas and Parnes 1999). Most recently, it has been shown that a single intratympanic injection of gentamicin is effective in the control of vertigo in most patients (Freedman and Sparks 1997).

Our study addresses the effect of such low doses of intratympanic gentamicin on vestibular function as measured by caloric tests and by the 3D angular vestibulo-ocular reflex (AVOR) elicited by rapid rotary head thrusts in the planes of the semicircular canals. Halmagyi and Curthoys (1988) introduced the head thrust test, demonstrating that subjects with complete surgical unilateral vestibular destruction (SUVD) on one side fail to maintain visual fixation on a target when the head undergoes a rapid rotation toward the lesioned side. The test relies on Ewald's second law which specifies that there is a greater effect from excitation of a semicircular canal than from inhibition of a canal (Ewald 1892). When the head is horizontally rotated toward the intact side in the head thrust test, the horizontal canal on the intact side is excited. The usual-but small-contribution of inhibition from the canal on the lesioned side is missing, but the response (eye velocity) generated by the excited canal is sufficient to yield a compensatory AVOR. However, when the head is horizontally rotated toward the lesioned side, the horizontal canal on the intact side is inhibited. Without the large excitatory contribution from the horizontal canal on the lesioned side, the asymmetry between excitation and inhibition becomes manifest, and the AVOR is noncompensatory.
The head thrust test has been quantitatively validated using magnetic search coil recordings of eye and head movements. AVOR gain values near 1.0 have been demonstrated in normal subjects (Aw et al. 1996a). Subjects with SUVD indeed have markedly diminished gains for head thrusts that would excite the canals on the lesioned side (Aw et al. 1996b). Head thrusts in the planes of the vertical semicircular canals likewise demonstrate hypofunction and can even isolate hypofunction affecting only one canal (Aw et al. 1995a,b; Cremer et al. 1998, 2000; Minor et al. 2001).

We used head thrusts in horizontal and vertical canal planes to measure the AVOR gains in cases of unilateral Ménière's disease before and after intralympanic gentamicin treatment, and we compared the post-gentamicin gains with those from control subjects who had complete SUVD. We found that even a single dose of intratympanic gentamicin caused marked decreases in the AVOR gains when head thrusts excited any of the treated canals. For the horizontal and the anterior canals, the asymmetries in gain between these canals and their contralateral mates caused by gentamicin treatment was significantly less than that caused by SUVD. These data indicate that intratympanic gentamicin may be physiologically less destructive than SUVD, perhaps because the spontaneous discharge rate and/or modulation with head motion are preserved in vestibular nerve afferents arising from the treated side after limited injections of gentamicin.

\section{METHODS}

Subjects

Subjects with Ménière's disease. Seventeen subjects (G117) were patients with "definite" unilateral Ménière's disease as defined by the 1995 criteria of the American Academy of Otolaryngology-Head and Neck Surgery (Monsell et al. 1995). ${ }^{1}$ The patients had experienced symptoms of vertigo, hearing loss in the affected ear, tinnitus, and/or aural fullness for $5 \pm$ 4 years [mean \pm standard deviation $(\mathrm{SD})$, range $=3-$ 15 years] prior to the intratympanic administration of gentamicin. Low-salt diets and diuretics failed to control their vertigo. Eight subjects were women and 9 were men, with ages ranging from 38 to 71 years $(55 \pm 15$, mean \pm SD). All subjects gave informed consent for the 3D AVOR recordings through a pro-

\footnotetext{
${ }^{1}$ Two or more spontaneous episodes of vertigo lasting $20 \mathrm{~min}$ or longer, hearing loss documented with an audiogram on at least one occasion, tinnitus or aural fullness in the affected ear, other pathologies excluded (Monsell et al. 1995).
} 
tocol approved by the Joint Committee on Clinical Investigation at the Johns Hopkins University School of Medicine, the institution at which treatment and testing were performed. Patients were tested 0-2 days prior to the first gentamicin treatment, except patient G6 who was tested 31 days prior to the first treatment. Post-gentamicin testing was performed 12-94 days after the final gentamicin treatment.

Subjects with surgical unilateral vestibular destruction (SUVD). Thirteen subjects were tested as controls with known complete unilateral vestibular hypofunction after surgical destruction of the peripheral vestibular system on one side. In 7 subjects the bony labyrinth was removed for surgical access to remove a vestibular schwannoma. In 2 subjects the superior and inferior vestibular nerves were sectioned as part of the removal of vestibular schwannomas via suboccipital craniotomy. In 4 subjects, the labyrinth had been surgically destroyed as treatment for intractable vertigo due to unilateral Ménière's disease.

\section{Protocol for gentamicin treatments}

Gentamicin was administered as we have previously described (Minor 1999). A radial myringotomy incision was made in the midposterior aspect of the tympanic membrane. The middle ear was filled with a buffered gentamicin solution $(26.7 \mathrm{mg} / \mathrm{mL}$ gentamicin, $0.4 \mathrm{~mL}$ typically injected). Patients remained supine with the bed angled slightly head down and the head turned to the contralateral side for $30 \mathrm{~min}$ to continually bathe the round window with gentamicin solution. The solution was then aspirated from the external canal and middle ear.

In the first 9 patients (subjects G1-9), the gentamicin injections were repeated at weekly intervals until patients developed spontaneous nystagmus, post-head-shaking nystagmus, or a head thrust sign. In patients who showed post-head-shaking nystagmus prior to treatment, the gentamicin injections were stopped when one of the other two signs developed. There were 5 patients who developed these signs after a single intratympanic injection, 2 who developed signs after 2 injections, and 2 who developed signs after 3 injections.

In the latter 8 subjects (G10-17), gentamicin was injected once, and the patients were assessed 3 weeks later to determine if they had symptoms and signs expected from the ablation of unilateral vestibular function. We made this modification in the dosing regimen for three reasons: (1) There is increasing evidence that a single intratympanic injection of gentamicin is effective in controlling vertigo in most patients (Harner et al. 2001). (2) Studies of gentamicin kinetics in hair cells indicate that, once inside the hair cell, gentamicin levels rise with cumulative dosing for periods of several weeks (Beaubien et al. 1995). (3) Both laboratory and clinical studies suggest that increasing the total intratympanic dose of aminoglycosides increases the risk of cochlear hair cell damage (Wanamaker et al. 1999) and the risk of profound sensorineural hearing loss (Kaplan et al. 2000). Complete control of vertigo was obtained after a single intratympanic injection of gentamicin in 7 of the 8 patients. For one patient in whom vertigo was not controlled (G15) by the single injection, two further gentamicin treatments were given at intervals of 3 and 2 months until vertigo was controlled.

Audiograms were also obtained before and after each treatment. Our previous experience with this protocol has shown that fewer than $5 \%$ of patients experience hearing loss as a consequence of the gentamicin treatment (Minor 1999). Long-term changes ( $>6$ months) in hearing after intratympanic gentamicin have not differed from the natural history of hearing loss in patients with Ménière's disease who have not received intratympanic gentamicin (Santos et al. 1993).

\section{Caloric tests}

Caloric tests were performed on subjects with Ménière's disease using a temperature switch irrigation technique for $30.5^{\circ} \mathrm{C}$ and $43.5^{\circ} \mathrm{C}$ (Proctor et al. 1975 ). Horizontal eye movements were recorded with electro-oculography, and maximum velocity of the slow-phase component of nystagmus was analyzed for unilateral weakness and directional preponderance as determined by conventional formulas (Jongkees et al. 1962). An ice water caloric test was performed when there was no response to warm or cold irrigation of the affected ear (100\% asymmetry). If nystagmus was noted in response to the ice water test, the subject was turned from supine to prone to see if the nystagmus reversed direction as expected based upon a convective mechanism.

\section{Head thrust tests}

The 3D AVOR for passive head thrusts was recorded in all subjects using magnetic search coils. Horizontal, vertical, and torsional components of the movement of one or both eyes were recorded using a dual search coil embedded in a silicone annulus that was placed around the cornea (Skalar, Delft, The Netherlands). The eyes were anesthetized with topical proparacaine prior to placement of the search coil. Another pair of search coils firmly attached to a bite bar sensed head movements. The bar consisted of a Plexiglas plate coated with hardened dental impres- 
sion compound molded to the subject's dental occlusion. The magnetic fields generating the voltages in the search coils were produced by three orthogonal pairs of coils, with a diameter and a distance of $1.02 \mathrm{~m}$. The techniques for search coil calibration and recording have been described previously (Straumann et al. 1995). In brief, eye and bite bar angular position signals were low-pass filtered with an analog, single-pole, Butterworth, anti-aliasing filter with a 3-dB bandwidth of $100 \mathrm{~Hz}$ and then digitally sampled at $500 \mathrm{~Hz}$. Eye and head velocities were derived by digital differentiation of the coil position signals with a 5th-order FIR filter limited to $30 \mathrm{~Hz}$.

The subject, seated with the head centered in the magnetic field, was instructed to gaze at a lightemitting diode (LED) located $124 \mathrm{~cm}$ directly forward at eye level. The examiner stood behind the subject and grasped the head over the temporoparietal area. The head was kept stationary in a comfortable, "upright" position prior to each head thrust. This position placed Reid's stereotactic line (inferior orbital rim to superior external auditory canal) $7^{\circ} \pm 7^{\circ}$ nose-up from the earth-horizontal plane. From this position the examiner rapidly rotated the head by $10-20^{\circ}$ in one of three planes: the earth-horizontal plane, the plane containing the left anterior and right posterior canals (LARP head thrusts), or the plane containing the right anterior and left posterior canals (RALP head thrusts). For horizontal head thrusts, the head was turned to the left to excite the left horizontal canal (HC) or to the right to excite the right HC. For LARP head thrusts, the head was turned down and counterclockwise (with respect to the subject) in the LARP plane to excite the LA canal or up and clockwise to excite the RP canal. For RALP head thrusts, the head was turned down and clockwise to excite the RA canal or up and counterclockwise to excite the LP canal. The subject knew which plane would be stimulated in each trial but could not predict the direction of the rotation. All patients were tested with horizontal head thrusts; vertical canal plane head thrusts were introduced later and used only in subjects G10-17.

\section{Calculation of gains}

Eye and head positions in three dimensions were expressed as rotation vectors and used to derive the angular velocities of the eye and head. We discarded data from head thrusts during which the eye responses included blinks, saccades, or eye movements that commenced before the onset of head movement. The starting point of the head thrust was taken when the measured head velocity exceeded the mean velocity at rest, which was close to $0^{\circ} / \mathrm{s}$, by $8 *$ standard deviation $+2^{\circ} / \mathrm{s}$ (Tabak et al. 1997a).
Angular positions and velocities were initially expressed in a Cartesian coordinate system obeying the right-hand rule with the $x$-axis aligned with the nasoocciptal axis, the $y$-axis aligned with the interaural axis, and the $z$-axis aligned with the earth-vertical axis. The positive ends of these axes pointed out the nose, left ear, and top of the head, respectively. We then rotated the coordinate system $+45^{\circ}$ around the $z$-axis so that the new coordinate axes roughly aligned with the axes of head rotation, axes that lay perpendicular to the canal planes (Cremer et al. 1998). The 3D eye and head velocity vectors then had components corresponding to each of the three canal planes.

For each head thrust, we calculated AVOR gain from the components of eye and head velocity along the axis of rotation. For example, gain for the HC pair was calculated from horizontal head thrusts using the component of eye velocity along the $z$-axis divided by the component of head velocity along the $z$-axis. Similarly, the gain for the LARP pair was calculated from LARP head thrusts, using the eye and head velocity components along the axis perpendicular to the LARP plane. Finally, the gain for the RALP pair was calculated from RALP head thrusts, using the eye and head velocity components along the axis perpendicular to that plane. As a representative "best value" of gain for each head thrust, we took the highest gain value that occurred in a 30 -ms period prior to peak head velocity. The eye velocities during this 30-ms period of analysis are highlighted in Figures 1-3. In cases where the gain was low, corrective and presumably nonvestibular eye movements sometimes occurred prior to peak head velocity (e.g., see arrow in Fig. 3; see also Tian et al. 2000). In such cases, the highest gain in the 30 -ms period before the onset of the early corrective eye movement was used instead. The rotational data were analyzed using MATLAB 5.3 (The Math Works Inc., Natick, MA).

Gain asymmetries (GA) for the AVOR were calculated for each coplanar canal pair using the general formula [(normal - affected)/(normal + affected) $] *$ $100 \%$, which is analogous to Jonkees' formula for caloric asymmetry (Jongkees et al. 1962). Here the "affected" canal refers to the canal on the side affected with Ménière's disease (in the pre-gentamicin group), treated with gentamicin (in the post-gentamicin group), or surgically deafferented (in the SUVD group $)$. For the horizontal canals, $\mathrm{GA}_{\mathrm{hor}}=\left[\left(\mathrm{G}_{\mathrm{chc}}-\right.\right.$ $\left.\left.\mathrm{G}_{\mathrm{ihc}}\right) /\left(\mathrm{G}_{\mathrm{chc}}+\mathrm{G}_{\mathrm{ihc}}\right)\right] * 100 \%$, where $\mathrm{G}_{\mathrm{chc}}$ is gain for head thrusts exciting the contralateral $\mathrm{HC}$ and $\mathrm{G}_{\mathrm{ihc}}$ is gain for head thrusts exciting the ipsilateral HC. For the $i$ psilateral anterior/contralateral posterior canal pair, $\mathrm{GA}_{\mathrm{iacp}}=\left[\left(\mathrm{G}_{\mathrm{cpc}}-\mathrm{G}_{\mathrm{iac}}\right) /\left(\mathrm{G}_{\mathrm{cpc}}+\mathrm{G}_{\mathrm{iac}}\right)\right]^{*} 100 \%$, where $G_{\text {cpc }}$ is gain for head thrusts exciting the contralateral PC and $G_{i a c}$ is gain for head thrusts exciting the ipsilateral AC. For the Ipsilateral anterior/con- 


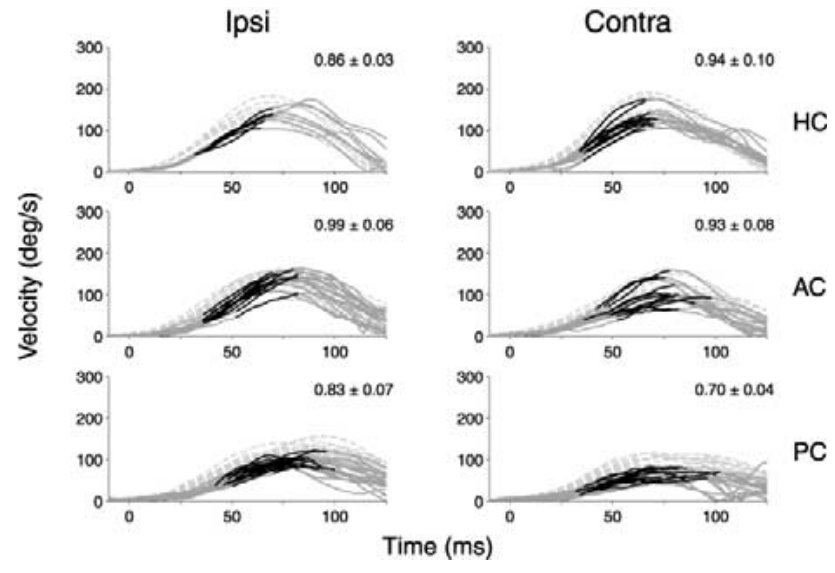

FIG. 1. Responses to head thrusts in subject G13 measured immediately before intratympanic gentamicin treatment. Each panel shows head velocity (light gray dashed) and eye velocity (dark gray and black) for rotations in the excitatory direction for each canal. Data from 8 to 12 stimulus repetitions are shown for each canal. Head velocity has been inverted to permit a direct comparison of the stimulus and the response. The interval over which gain was analyzed (30 ms prior to peak head velocity) is shown in black for each trace. The eye velocity before and after this analysis interval is shown in dark gray. A gain value was calculated as eye/head velocity for every point in time during the analysis interval. The response gain for each stimulus repetition was defined as the maximum gain value during the interval of analysis. The response gain (mean \pm SD for all stimulus repetitions) is given in each panel's upper right corner.

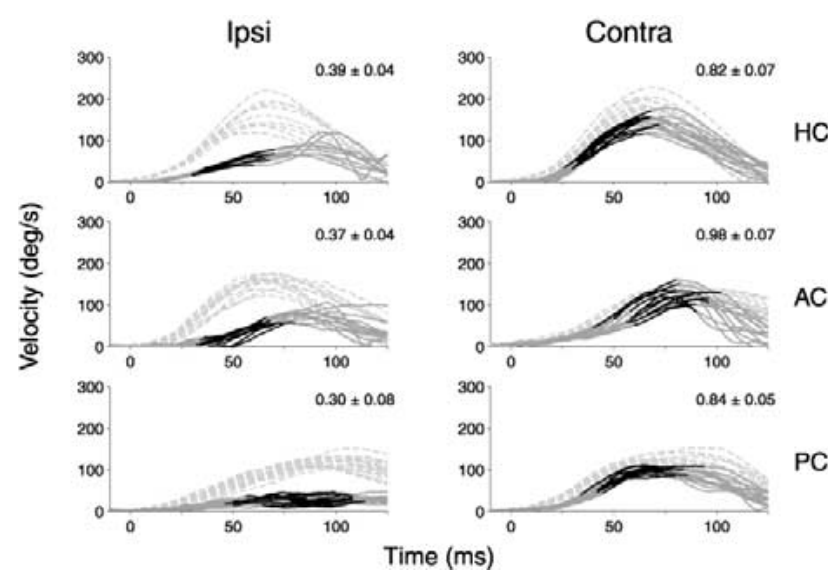

FIG. 2. Responses to head thrusts that excited each of the 6 semicircular canals in subject G13 (same as in Fig. 1) measured 49 days after a single intratympanic injection of gentamicin. Panels, traces, and gain values are as described for Figure 1.

tralateral posterior canal pair, $\mathrm{G}_{\mathrm{ipca}}=\left[\left(\mathrm{G}_{\mathrm{cac}}-\mathrm{G}_{\mathrm{ipc}}\right) /\right.$ $\left.\left(\mathrm{G}_{\mathrm{cac}}+\mathrm{G}_{\mathrm{ipc}}\right)\right] * 100 \%$, where $\mathrm{G}_{\mathrm{cac}}$ is gain for head thrusts exciting the contralateral $A C$ and $G_{i p c}$ is gain for head thrusts exciting the ipsilateral PC.

\section{Data analysis}

Gain values and gain asymmetries were compared between subjects with Ménière's disease before and

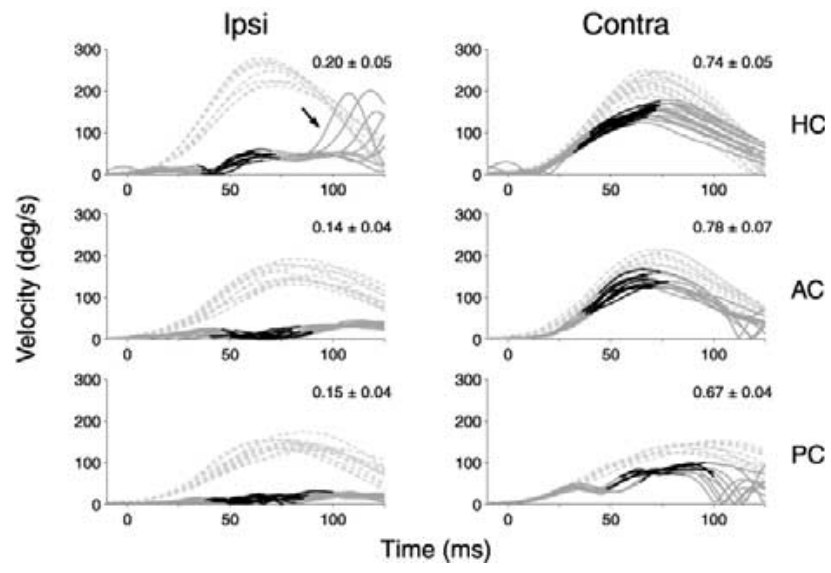

FIG. 3. Responses to head thrusts that excited each of the 6 semicircular canals in a subject tested one year after translabyrinthine removal of a left vestibular schwannoma. Panels, traces, and gain values are as described for Figure 1. Note the rapid eye movements that correct for gaze position errors in the responses to the head thrusts that are excitatory for the ipsilateral horizontal canal (arrow).

after treatment with intratympanic gentamicin using two-tailed paired $t$-tests of the means, assuming unequal variances. Unpaired $t$-tests were used to compare gains and gain asymmetries between subjects with Ménière's disease after treatment with intratympanic gentamicin and subjects with SUVD. Mean head velocities and accelerations for different head thrusts in the different treatment groups were compared using a two-way analysis of variance (ANOVA). Statistical calculations were performed using MS Excel 2000 (Microsoft Corporation, Redmond, WA).

\section{RESULTS}

\section{Control of vertigo}

The subjects with Ménière's disease in this study had experienced $23 \pm 13$ episodes of vertigo during the 3 months prior to receiving intratympanic gentamicin. During the 6 months immediately following this treatment, 16 of the 17 subjects experienced no episodes of vertigo (complete control as defined by the 1995 AAOHNS criteria). One subject (G15) continued to experience episodes of vertigo after a single intratympanic injection of gentamicin. Two additional gentamicin injections in the affected ear were given 112 and 54 days later, at which point her vertigo was controlled.

\section{Spontaneous nystagmus}

Spontaneous nystagmus in darkness was observed at the time of 3D eye movement recordings in each patient after gentamicin treatment. However, the 
slow-phase velocity was always less than $2 \%$ s. In each case the horizontal slow phases of nystagmus were directed toward the treated side, as expected for hypofunction on the treated side.

\section{Evaluation of the AVOR before and after}

intratympanic gentamicin in a single subject

Figure 1 shows representative head (dashed gray) and eye (solid gray) velocity traces for subject G13 tested prior to gentamicin treatment. This 38-yearold woman had a 3-year history of episodic vertigo as well as right fluctuating sensorineural hearing loss and tinnitus. She had experienced 12 episodes of vertigo during the 3 months prior to intratympanic gentamicin. Her symptoms had not been controlled with a salt-restricted diet and diuretics. Her caloric tests showed a $23 \%$ right unilateral vestibular weakness.

Each panel of Figure 1 shows the traces of subject G13's eye and head velocities for head thrusts that excited the indicated canal. For example, panels in the column labeled "Ipsi" show the AVOR for head thrusts that excited the canals on the side affected with Ménière's disease. For ease of comparison, the signs of the eye and head velocity traces have been given as positive values in all panels. Despite the presence of Ménière's disease, the AVOR gains for excitation of the affected canals remained high. In the 30-ms period prior to peak head velocity (indicated by the darkened area of each eye velocity trace), the maximum gain values (eye velocity/head velocity) were $0.86 \pm 0.03$ for excitation of the $\mathrm{HC}, 0.99 \pm 0.06$ for excitation of the $\mathrm{AC}$, and $0.83 \pm 0.07$ for excitation of the PC on the affected side.

Panels in the column labeled "Contra" show data for head thrusts exciting the contralateral canals. The AVOR was again robust for excitation of the contralateral HC (gain $=0.94 \pm 0.10)$ and $\mathrm{AC}$ (gain $=0.93 \pm$ $0.08)$. Excitation of the contralateral PC yielded an AVOR with a lower gain $(0.70 \pm 0.04)$.

Figure 2 shows data from the same subject 49 days after a single injection of gentamicin into the right middle ear. Four days after the treatment she developed dysequilibrium that resolved over the course of several weeks. She did not experience any further episodes of vertigo after the single dose. Following gentamicin treatment, her caloric tests showed a $92 \%$ unilateral vestibular weakness on the right side. Her AVOR data also showed marked decrements in the gains for head thrusts that excited any of the treated canals. Gain for excitation of the treated HC decreased to $0.39 \pm 0.04$, for the treated AC to $0.37 \pm 0.04$, and for the treated PC to $0.30 \pm 0.08$ $(p<0.001$ with respect to pretreatment values in each case).
Her AVOR gains for excitation of the contralateral canals also changed, but much less. The mean gain for excitation of the contralateral HC decreased to $0.82 \pm 0.07(p=0.006)$. The gain of the contralateral PC was $0.84 \pm 0.05$, higher than that noted prior to intratympanic gentamicin $(p<0.001)$, and the contralateral AC showed a small, but statistically insignificant, increase.

\section{Evaluation of the AVOR in a subject with SUVD}

Figure 3 demonstrates the performance of the AVOR for head thrusts in a subject with SUVD. The subject was a 66 -year-old man who had a small $(4 \mathrm{~mm} \times 8$ $\mathrm{mm}$ ) left vestibular schwannoma resected via translabyrinthine approach 1 year prior to AVOR testing. In the column labeled "Ipsi" are data from head thrusts that would have excited the canals on the side of surgery. The eye velocities for these ipsilesional head thrusts are minimal, with average gains for excitation of the $\mathrm{HC}$ of $0.20 \pm 0.05$, for the AC of $0.14 \pm$ 0.04 , and for the PC of $0.15 \pm 0.04$. In the column labeled "Contra," data for contralesional head thrusts show a more robust AVOR, with excitation of the $\mathrm{HC}$ yielding an average gain of $0.74 \pm 0.05$; of the $\mathrm{AC}, 0.78 \pm 0.07$; and of the PC, $0.67 \pm 0.04$. The asymmetries between the gains for ipsilesional in comparison to contralesional head thrusts were $58 \%$ for $\mathrm{GA}_{\mathrm{hc}}, 64 \%$ for $\mathrm{GA}_{\mathrm{iacp}}$, and $68 \%$ for $\mathrm{GA}_{\mathrm{ipca}}$.

Evaluation of the AVOR in the group of subjects with Ménière's disease before and after intratympanic gentamicin

AVOR responses measured before intratympanic gentamicin injection in the 17 subjects with unilateral Ménière's disease generally mimicked the compensatory gains seen in Figure 1. The AVOR gains measured in these individual subjects for head thrusts that excited the ipsilateral canals are plotted beneath the label "PRE" in Figure 4, and Table 1 summarizes the means and standard deviations of these gains. The AVOR gains for head thrusts that excited the contralateral canals are plotted in Figure 5.

Prior to gentamicin treatment, no significant asymmetries were found between gains for head thrusts that excited canals ipsilateral to the Ménière's disease and their functionally paired mates on the contralateral side (Table 1). Despite the presence of active Ménière's disease, the AVOR gains for head thrusts to either side in these subjects were similar to those reported for normal subjects (Aw et al. 1996b).

Gentamicin injections resulted in large and significant decreases in AVOR gains for head thrusts that excited each of the ipsilateral canals (data 


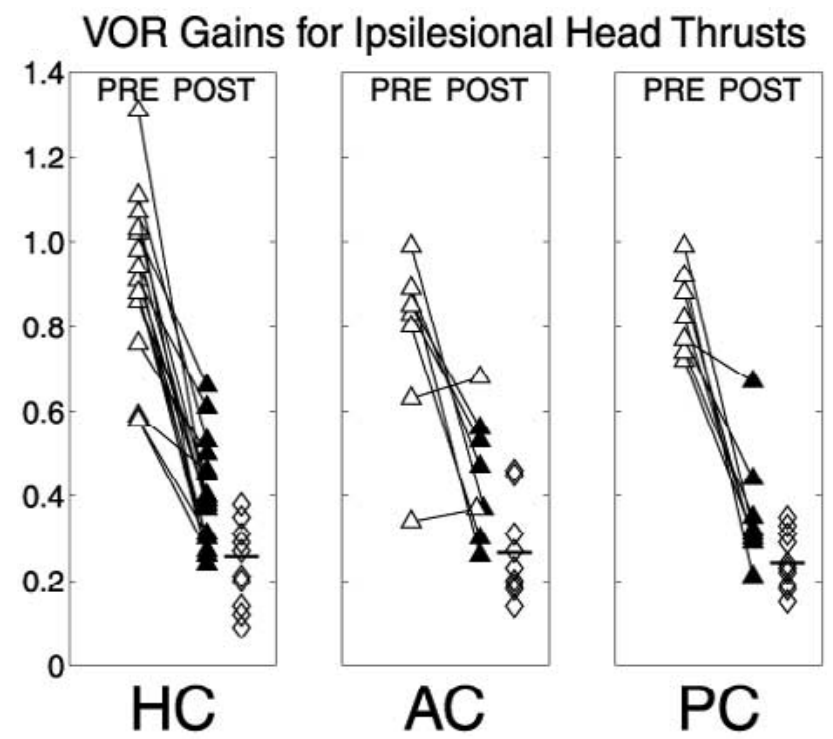

FIG. 4. Comparison of gain values measured in 17 subjects with unilateral Ménière's disease for head thrusts that excited the semicircular canals on the affected side prior to intratympanic gentamicin treatment (PRE) and following treatment (POST). Triangles represent mean gain values from individual subjects with Ménière's disease, and each line connects pre- and post-gentamicin values for one subject. Filled triangles in the POST data indicate decreased gains compared with PRE values $(p<0.01)$. The open diamonds show gain values for head thrusts toward the lesioned side in SUVD subjects. The horizontal bar on each plot gives the mean gain value for the SUVD subjects.

labeled "POST" in Fig. 4). Mean gain for the ipsilateral $\mathrm{HC}$ decreased to $44 \%$ of its pre-gentamicin value; for the ipsilateral $\mathrm{AC}$, to $45 \%$; and for the ipsilateral PC, to $38 \%$ (Table 1). Among individual subjects, gain for excitation of the ipsilateral $\mathrm{HC}$ decreased in each of 17 cases $(p<0.01$, indicated by filled symbols in the "POST" data of Fig. 4). Likewise, gain for excitation of the treated PC decreased in each of the 8 subjects for whom diagonal vertical head thrusts were performed. Gain for excitation of the treated AC decreased in 6 of these 8 subjects.

For excitation of the contralateral canals, a slight decrease in mean gain was observed only for the HC canal (to $87 \%$ of its pretreatment value, Table 1). Among the individual subjects, small decreases in gain $(p<0.01$, indicated by filled "POST"' symbols in Fig. 5) were noted for the contralateral $\mathrm{HC}$ in 11 of 17 subjects, for the contralateral AC in 5 of 8 , and for the contralateral PC in 3 of 8 .

As noted above, subject G15 continued to have episodes of vertigo after the first intratympanic gentamicin treatment. Her AVOR gain values for head thrusts that excited the semicircular canals on the affected side prior to intratympanic gentamicin were as follows: $\mathrm{HC}=0.59 \pm 0.03, \mathrm{AC}=0.63 \pm 0.05$, and $\mathrm{PC}=0.77 \pm 0.05$. When tested 14 days after the first gentamicin injection, the gain values for canals on the treated side were $\mathrm{HC}=0.77 \pm 0.08, \mathrm{AC}=0.61$ \pm 0.06 , and $\mathrm{PC}=0.87 \pm 0.06$. The gain values for the HC and the PC were actually higher after than before the single injection of gentamicin $(p<0.01)$. She received two additional intratympanic gentamicin treatments until her vertigo was controlled, and the AVOR gains for canals on the treated side (measured 94 days and after the final injection) were as follows: $\mathrm{HC}=0.46 \pm 0.03, \mathrm{AC}=0.68 \pm 0.05$, and $\mathrm{PC}=0.44 \pm 0.05 \quad(p<0.001$ with respect to values after the first injection of gentamicin). These gains values after the third gentamicin injection were used in compiling the group data for responses after treatment (Table 1).

Comparison of AVOR gains after intratympanic gentamicin and after SUVD

The open diamonds in Figures 4 and 5 represent the mean gain values from individuals with SUVD, and the horizontal bars represent the averages from these individuals. As indicated in Table 1, head thrusts that excited the $\mathrm{HC}$ and AC on the gentamicin-treated side had AVOR gain values that were higher than the corresponding SUVD gain values. For head thrusts that excite the canals contralateral to the lesion, only the postgentamicin gains for excitation of the contralateral HC were significantly higher than corresponding SUVD values $(0.80 \pm 0.11$ vs. $0.70 \pm 0.14, p=0.04)$.

Gain asymmetries after intratympanic gentamicin in comparison to those after SUVD

We calculated gain asymmetries (GA) between canals on the side affected with Ménière's disease and their coplanar mates on the unaffected side. This measurement permits a comparison of the asymmetry in the AVOR between the two sides, independent of absolute gain values, in each individual, analogous to the Jonkees formula for calculating caloric asymmetry (Jongkees et al. 1962). Table 1 (right side) summarizes the changes in means and standard deviations for the GA values. Prior to gentamicin treatment, there was little asymmetry in the gain values for head thrusts that excited affected versus unaffected canals for any of the canal planes. Following intratympanic gentamicin treatment, $\mathrm{GA}_{\mathrm{hc}}$ increased to $34 \%$, $\mathrm{GA}_{\text {iacp }}$ to $24 \%$, and $\mathrm{GA}_{\text {ipca }}$ to $42 \%$. Comparison of these asymmetries with those obtained for head thrust tests in subjects with SUVD also showed a difference between the effects of these two types of lesions on AVOR function. As indicated by the significance symbols in Table 1, GA was higher after SUVD than after intratympanic gentamicin treatment for the HC pair and for the ipsilateral anterior/contralateral posterior canal pair. There- 
TABLE 2

Clinical details and comparisons of caloric and AVOR gain asymmetries in subjects with Ménière's disease tested before and after treatment with intratympanic gentamicin

\begin{tabular}{|c|c|c|c|c|c|c|}
\hline \multirow[b]{2}{*}{ Series no. } & \multirow[b]{2}{*}{ No. treatments } & \multirow[b]{2}{*}{$\begin{array}{l}\text { Days between } \\
\text { treatment \& testing }\end{array}$} & \multicolumn{2}{|c|}{ Before gentamicin } & \multicolumn{2}{|c|}{ After gentamicin } \\
\hline & & & $\begin{array}{c}\text { Caloric asymmetry } \\
(\%)\end{array}$ & $\begin{array}{c}\text { Gain asymmetry } \\
\text { for HC (\%) }\end{array}$ & $\begin{array}{c}\text { Caloric asymmetry } \\
(\%)\end{array}$ & $\begin{array}{c}\text { Gain asymmetry } \\
\text { for HC (\%) }\end{array}$ \\
\hline G1 & 1 & 23 & 100 & -1 & 100 & 45 \\
\hline G2 & 1 & 22 & 24 & -2 & 100 & 31 \\
\hline G3 & 3 & 20 & 37 & -4 & 83 & 15 \\
\hline G4 & 2 & 14 & 67 & 1 & 79 & 32 \\
\hline G5 & 1 & 26 & $100^{\mathrm{a}}$ & 3 & Not tested & 38 \\
\hline G6 & 3 & 23 & 18 & -3 & $100^{\mathrm{a}}$ & 36 \\
\hline G7 & 2 & 12 & 32 & 14 & 72 & 32 \\
\hline G8 & 1 & 15 & 44 & -10 & 70 & 53 \\
\hline G9 & 1 & 34 & 37 & 8 & $100^{\mathrm{a}}$ & 54 \\
\hline G10 & 1 & 32 & 25 & -15 & $100^{\mathrm{a}}$ & 20 \\
\hline G11 & 1 & 42 & 16 & 7 & 44 & 23 \\
\hline G12 & 1 & 49 & 3 & 3 & 100 & 31 \\
\hline G13 & 1 & 49 & 23 & 5 & $100^{\mathrm{a}}$ & 36 \\
\hline G14 & 1 & 28 & $100^{\mathrm{a}}$ & 27 & Not tested & 51 \\
\hline G15 & 3 & 94 & 37 & 22 & 100 & 29 \\
\hline G16 & 1 & 34 & 32 & -11 & 100 & 42 \\
\hline G17 & 1 & 70 & -8 & -11 & $100^{\mathrm{a}}$ & 18 \\
\hline
\end{tabular}

${ }^{a} \mathrm{No}$ response to ice water irrigation as well as to $30.5^{\circ} \mathrm{C}$ and $43.5^{\circ} \mathrm{C}$ stimulation. Either no nystagmus developed with ice water irrigation of these treated ears or the slow-phase components were directed ipsilaterally but did not reverse in direction upon moving the subjects from supine to prone. Such a reversal would have been expected if the stimulus had caused nystagmus by convective flow of endolymph. Instead, a direct thermal effect on the vestibular afferents was assumed.

cool caloric stimulation but who had a response to ice water irrigation in the treated ear when testing was performed in the supine position. The slow-phase components of this nystagmus were directed toward the treated ear, and the slow-phase velocity measured $7 \pm 4^{\circ} /$ s. The nystagmus did not reverse direction upon moving the subject from supine to prone in any subject. This finding indicates that the ice water response was not due to convective flow of endolymph in the horizontal canal. A direct effect of temperature on hair cells and/or vestibular nerve afferents may be the underlying mechanism (Paige 1985; Minor and Goldberg 1990). Alternatively, the ice water caloric stimulus may have unmasked an underlying spontaneous nystagmus.

We found no relationship between the presence or absence of caloric responses after gentamicin treatment and the gain for excitation of the ipsilateral HC on head thrust testing. For the 10 subjects who lost the ipsilateral caloric response following gentamicin treatment, AVOR gain for excitation of the treated $\mathrm{HC}$ was $0.40 \pm 0.11$. For the 5 subjects who still had an ipsilateral caloric response after gentamicin treatment, AVOR gain for excitation of the treated $\mathrm{HC}$ measured $0.41 \pm 0.17(p=0.8)$.

\section{Comparisons of head thrusts used in different} groups of subjects

AVOR gain can vary depending on the head velocity and acceleration at the time when gain is measured
(Aw et al. 1996a). We compared the peak head velocities and accelerations for the head thrusts used in each group of subjects to see if there were systematic biases that might be expected to produce any of the differences observed between groups or canals. Table 3 gives the peak head velocities and accelerations for these groups. Velocities and accelerations for ipsi- and contralateral canals of the same type (HC, AC, or PC) were averaged together because there were minimal differences in the dynamics for head thrusts exciting an individual canal on one side in comparison to head thrusts exciting the same canal on the other side. For the three groups of subjects there were no differences between the peak head velocities $(p=0.11)$ and accelerations $(p=0.19)$ used for testing a given canal (2-way ANOVA, effect of rows in Table 3). These findings indicate that, for a given canal, differences in stimuli were not responsible for the observed differences in gain values between the groups of subjects. We did find that our manual head thrusts in the diagonal vertical planes had lower peak head velocities $(p=0.0007)$ and accelerations $(p=0.0003)$ than did our horizontal head thrusts (2way ANOVA, effect of columns in Table 3). However, these peak velocities and accelerations as well as the variability between head thrusts are comparable to those reported in other studies that have used manual head thrusts (Schmid-Priscoveanu et al. 2001; Aw et al. 1996b; Cremer et al. 1998). In particular, the head accelerations exceeded $3000^{\circ} / \mathrm{s}^{2}$ for all head thrusts. 
TABLE 3

\begin{tabular}{|c|c|c|c|c|c|c|}
\hline \multicolumn{7}{|c|}{ Peak head velocities $(\% / s)$ and acceleration $\left(\% / s^{2}\right)^{a}$} \\
\hline & \multicolumn{3}{|c|}{ Peak head velocity $(\% / s)$} & \multicolumn{3}{|c|}{ Peak head acceleration $\left(\% / \mathrm{s}^{2}\right)$} \\
\hline & $H C$ & $A C$ & $P C$ & $H C$ & $A C$ & $P C$ \\
\hline Before gentamicin & $186 \pm 39$ & $164 \pm 19$ & $146 \pm 27$ & $4530 \pm 1520$ & $3964 \pm 1160$ & $3510 \pm 1148$ \\
\hline After gentamicin & $198 \pm 39$ & $176 \pm 19$ & $152 \pm 25$ & $4779 \pm 1798$ & $3938 \pm 1065$ & $3387 \pm 1142$ \\
\hline SUVD & $202 \pm 34$ & $176 \pm 20$ & $144 \pm 9$ & $4480 \pm 1512$ & $3815 \pm 870$ & $3300 \pm 935$ \\
\hline
\end{tabular}

${ }^{a}$ Values are means \pm SD.

\section{DISCUSSION}

We investigated the changes in the gain of the AVOR that occurred before and after 1-3 intratympanic injections of gentamicin for control of vertigo in unilateral Ménière's disease. Using head thrusts in the horizontal plane and in the diagonal vertical canal planes, we evaluated the AVOR generated by each of the orthogonal pairs of semicircular canals. There were three remarkable findings. First, Ménière's disease itself had a minimal effect on the AVOR gains for head thrusts that excited the canals on the affected side. Second, treatment with intratympanic gentamicin, even as little as a single dose, markedly reduced the AVOR gains for head thrusts that excited canals on the treated side. Third, the reduction of AVOR gains after intratympanic gentamicin treatment was not as severe as that seen after surgical destruction of the labyrinth.

We first discuss the implications that these three findings might have for our understanding of the effects of Ménière's disease and gentamicin on the labyrinth. We then discuss how the effects of intratympanic gentamicin differ from those of the surgically destructive treatments for Ménière's disease. Finally, we consider the clinical implications of these findings, including the number of doses of gentamicin that should be given and the implications for control of vertigo.

\section{Effect of Ménière's disease on the AVOR prior to intratympanic gentamicin treatment}

Despite longstanding unilateral Ménière's disease, most subjects tested prior to treatment with intratympanic gentamicin had gain values attributable to each of the semicircular canals that were comparable to those previously reported in normal subjects (Tabak et al. 1997a; Tian et al. 2001; Aw et al. 1996b; Cremer et al. 1998). In the present study, 13 of the 17 subjects with Ménière's disease had horizontal AVOR gain values $>0.8$, regardless of whether the head thrusts were directed so as to excite the canals ipsilateral to the Ménière's disease or contralateral to it
(Figs. 4 and 5). We first consider whether or not these compensatory AVOR gains arose from preserved vestibular function in the ears affected with Ménière's disease.

One hypothesis to explain these AVOR gains for head thrusts exciting the affected semicircular canals is that these responses are generated from the inhibitory signal arising from the contralateral side. However, other studies have found that SUVD produces a permanent asymmetry in the AVOR in response to rapid transient head rotations toward the lesioned side (Curthoys et al. 1995; Tabak et al. 1997b; Gilchrist et al. 1998; Crane and Demer 1998; Lasker et al. 2000). These findings indicate that the central pathways responsible for control of the AVOR cannot effectively use the inhibitory signals from the intact side to generate a compensatory response for head thrusts. Our own data from SUVD subjects confirmed this finding, showing large asymmetries in gains for excitation of the ipsilateral versus contralateral canals. Furthermore, if the signals from the healthy ears were responsible for the compensatory AVOR gains in our subjects with Ménière's disease, then treatment of their affected ears should have had little further effect on AVOR gains. We instead observed a marked effect of intratympanic gentamicin on AVOR gains for excitation of the semicircular canals on the treated side. We conclude, therefore, that our subjects with active Ménière's disease retained significant vestibular function in the affected ears prior to gentamicin injection.

The clinical findings in these patients provide further evidence of retained vestibular function in the affected ear. If all vestibular function were lost, patients might be expected to have oscillopsia and instability with rapid head movements, but the spontaneous attacks of vertigo would not have been expected. There is also anatomic support for the notion of preserved vestibular function in ears that have longstanding Ménière's disease. Tsuji et al. (2000) examined temporal bones from 24 patients with Ménière's disease. While the loss of type II hair cells and Scarpa's ganglion cells were greater than expected for age, they rarely observed $>50 \%$ reduc- 
tion in either type of hair cell or the afferent neurons. Moreover, there was no detectable effect of duration of symptoms on the density of hair cells or ganglion cells, even though some patients had symptoms for more than 20 years.

Our findings reveal differences between the magnitudes of dysfunction in the affected ear measured by caloric tests and by head thrust tests prior to intratympanic gentamicin. While the AVOR gain for horizontal head thrusts was normal in 15 of the 17 subjects with Ménière's disease, the caloric sensitivity of the affected horizontal canal was diminished in 13 of the 17. There are several possible explanations for the discrepancies between the results of caloric and head thrust tests in this disorder. Ménière's disease may cause a differential reduction in the sensitivity of vestibularnerve afferents in the affected ear, with responses to stimuli that have comparatively low frequency, velocity, and acceleration (calorics) being reduced more than responses to stimuli with high frequency, velocity, and acceleration (head thrusts). The low velocity and acceleration of endolymph movement resulting from a caloric stimulus would then be insufficient to generate a normal response. However, the high velocity and acceleration of endolymph flow resulting from a head thrust would be adequate to generate a compensatory eye response. A second possibility is that the response to head velocity by vestibularnerve afferents in Ménière's disease is diminished for stimuli of both high and low frequency and amplitudes, but the central gain for inputs of high frequency and amplitude is greater.

\section{Effects of intratympanic gentamicin on the AVOR}

In contrast to the pre-gentamicin findings, after treatment we found uniform reductions in the AVOR gains elicited by head thrusts that excited canals on the treated side. By measuring AVOR gains in each subject before and after treatment with intratympanic gentamicin, we were able to use each individual as his or her own control. As previously discussed, the appearance of diminished AVOR gain values only after treatment indicates that the effect of gentamicin on the AVOR is due specifically to a reduction in function of the treated labyrinth.

We also compared the AVOR gain value for excitation of each canal on the treated side with the gain value for excitation of its coplanar mate on the intact side. This calculation of gain asymmetry accounted for any generalized (i.e., bilateral) decrease in AVOR gain as a response to the loss of unilateral function. Gain asymmetries increased markedly after intratympanic gentamicin because the gains for ipsilesional responses were reduced by $53 \%-61 \%$ in comparison to pretreatment values, whereas contralesional re- sponses were reduced by only $9 \%-13 \%$. These findings provide further evidence that the effect of gentamicin was specific to the treated labyrinth.

Gentamicin most likely reduces peripheral vestibular function by direct toxic effects on hair cells. The precise cellular targets of aminoglycosides for their ototoxic effects are not known, but damage may involve binding to plasma membrane phospholipids, inactivation of the enzyme ornithine decarboxylase, competitive blockade of calcium channels, or binding to iron and formation of oxygen free radicals (Schacht 1993; Song et al. 1998). The effects of gentamicin on vestibular hair cells have been extensively evaluated in chinchillas (Lopez et al. 1997, 1998). Application of $50 \mu \mathrm{g}$ of gentamicin into the perilymph of the superior semicircular canal of chinchillas resulted in a marked reduction of both type I and type II hair cells by 2 weeks after treatment. When histological examinations were made 2-4 weeks after gentamicin treatment, a significant number of type II, but not type I, hair cells were noted. These findings indicate that small doses of gentamicin within the labyrinthine fluids cause substantial hair cell injury over the time period addressed in our study. The effects of gentamicin on the responses of vestibularnerve afferents in similar experimental conditions remain to be determined.

Comparison of responses to head thrusts after gentamicin and after SUVD

We found that the AVOR gains for head thrusts that excite canals on the gentamicin-treated side exceeded those seen for the same stimuli in subjects with SUVD and that gain asymmetries were smaller after gentamicin than after SUVD. These differences between SUVD and gentamicin treatment suggest that gentamicin might not cause complete hair cell destruction. Thus, modulation of afferent firing rate with head movement might return, but with lower sensitivity or fewer activated fibers than prior to treatment. These signals encoding head movement might be further amplified by central adaptation to produce the higher AVOR gains seen in gentamicintreated subjects.

A second possible mechanism to explain the higher gains in gentamicin-treated subjects is the preservation or return of spontaneous activity, but not of activity modulated by head movements, in the vestibularnerve afferents on the treated side. Hair cells might recover their secretory activity independent of their mechanotransduction function if damage to their cuticular plates and stereocilia was extensive and persistent but the basolateral surfaces remained viable. Zheng et al. (1999) found just such a pattern of damage to hair cells in rat utricles 
exposed to gentamicin in culture. Using immunohistochemical and ultrastructural techniques to differentiate complete hair cell loss from loss of stereocilia, they found that approximately half of the hair cell bodies remained viable in the epithelium despite loss of their stereocilia and that stereociliary bundles recovered during an 11-day period after gentamicin exposure in approximately $20 \%$ of hair cells. Mechanically traumatized auditory hair cells in the mouse organ of Corti also lose their apical specializations, including the cuticular plate and stereocilia, but still survive deep in the epithelium and maintain contact with their underlying afferents (Sobkowicz et al. 1996). Preservation or recovery of baseline hair cell synaptic activity, despite little or no modulation related to head movement, might lead to more symmetry in responses to high-acceleration stimuli because of less static imbalance in the resting activity between the two sides.

\section{Clinical implications}

Effects of number of gentamicin injections on vestibular function. The reduction in function in the semicircular canals on the treated side after gentamicin was comparable between patients who received a single injection and those who received multiple weekly injections. This finding supports the notion that gentamicin exerts its effect on vestibular function over a period of several days to weeks after instillation into the middle ear. For weekly injections (Minor 1999), the effect may not have been apparent at the one-week followup visit because the initial dose had not yet caused sufficient structural or physiological changes to measurably affect the function of the labyrinth.

Following a single intratympanic administration, gentamicin enters the inner ear, likely through the round window membrane, and is measurable in perilymph for only about 48 hours (Hoffer et al. 2001). Hair cells take up the drug and sequester it in lysosomes. The cellular metabolism may not be affected until these lysosomes rupture, an event that may happen at prolonged and variable times (Hashino et al. 1997). Such a mechanism could explain the clinical observation of prolonged and variable times between the injection of gentamicin and the appearance of measurable vestibular hypofunction. In the present study, additional doses of gentamicin did not result in greater loss of function than did a single dose. It is possible, therefore, that a single intratympanic injection of gentamicin sufficiently saturates hair cell receptors to ensure ototoxic damage.

Is vestibular hypofunction necessary for control of vertigo in Ménière's disease? This study shows that control of vertigo following intratympanic gentamicin was associated with a marked reduction of semicircular canal function on the treated side. Indeed, the one subject (G15) who did not have a reduction in AVOR gain after a single intratympanic gentamicin treatment continued to experience episodes of vertigo. Her vertigo was brought under control only after two additional intratympanic injections of gentamicin were administered. After the third injection, her AVOR gains for head thrusts exciting the canals on the treated side were reduced to values that were comparable to other patients in this study.

It has been suggested that gentamicin may exert its beneficial effect in Ménière's disease by impairing the secretory function of dark cells (the principal endolymph-producing cells in the inner ear), thus limiting the production of endolymph (Park and Cohen 1982, 1984; PFender 1985). This possibility seems unlikely given the findings of a recent morphological study in chinchillas demonstrating little change in dark cells following administration of gentamicin or streptomycin (Chen et al. 1999). While our study does not establish a causal link between reduction of vestibular function and control of vertigo, it is notable that even a single dose of intratympanic gentamicin routinely causes a marked reduction in semicircular canal function.

We will continue to follow these patients and to measure their AVOR function to determine whether or not the reduction in semicircular canal function is permanent. The higher AVOR gains that we observed after gentamicin treatment compared with those seen after SUVD are especially intriguing. It will be important to learn if the apparent preservation of some vestibular function after intratympanic gentamicin treatment is of clinical benefit to patients. Such function might allow patients to improve their vestibular reflexes and compensatory strategies.

\section{ACKNOWLEDGMENTS}

Supported by NIH R01 DC02390, P60 DC00979, and the Research Fund of the American Otological Society.

\section{REFERENCES}

AtLAS JT, PARnEs LS. Intratympanic gentamicin titration therapy for intractable Ménière's disease. Am. J. Otol. 20:357-363, 1999.

Aw ST, Halmagy GM, Haslwanter T, Curthoys IS, Yavor RA, Todd MJ. Three-dimensional vector analysis of the human vestibuloocular reflex in response to high acceleration head rotations. II. Responses in subjects with unilateral vestibular loss and selective semicircular canal occlusion. J. Neurophysiol. 76:4021-4030, 1996 a.

Aw ST, Halmagy GM, Pohl DV, Curthoys IS, Yavor RA, Todd MJ. Compensation of the human vertical vestibulo-ocular reflex 
following occlusion of one vertical semicircular canal is incomplete. Exp. Brain Res. 103:471-475, 1995 a.

Aw ST, Halmagy GM, Pohl DV, Gurthoys IS, Yavor RA, Todd MJ. The effect of unilateral posterior semicircular canal inactivation on the human vestibulo-ocular reflex. Acta Otolaryngol. Suppl. (Stockh.) 520:260-262, 1995b.

Aw ST, Haslwanter T, Halmagy IS, Curthoys RA, Yavor RA, Todd MJ. Three dimensional vector analysis of the human vestibuloocular reflex in response to high-acceleration head rotations. I. Responses in normal subjects. J. Neurophysiol. 76:4009-4020, 1996b.

Beaubien AR, Karpinski K, Ormsby E. Toxicodynamics and toxicokinetics of amikacin in the guinea pig cochlea. Hear. Res. 83:62-79, 1995.

Beск C, SсHмidT CL. 10 years of experience with intratympanally applied streptomycin (gentamicin) in the therapy of Morbus Meniere. Arch. Otorhinolaryngol. 221:149-152, 1978.

Chen JM, Kakigi A, Hirakawa H, Mount RJ, Harrison RV. Middle ear instillation of gentamicin and streptomycin in chinchillas: Morphologic appraisal of selective ototoxicity. J. Otolaryngol. 28:121-128, 1999.

Crane BT, Demer JL. Human horizontal vestibulo-ocular reflex initiation: Effects of acceleration, target distance, and unilateral deafferentation. J. Neurophysiol. 80:1151-1166, 1998.

Cremer PD, Halmagi GM, Aw ST, Curthoys is, McGarvie LA, Todd MJ, Black RA, Hannigan IP. Semicircular canal plane head impulses detect absent function of individual semicircular canals. Brain 121:699-716, 1998.

Cremer PD, Minor LB, Carey JP, Della SC, Sontina CG. Eye movements in patients with superior canal dehiscence syndrome align with the abnormal canal. Neurology 55:1833-1841, 2000.

Curthoys IS, Topple AN, Halmagy GM. Unilateral vestibular deafferentation (UVD) causes permanent asymmetry in the gain of the yaw VOR to high acceleration head impulses in guinea pigs. Acta Otolaryngol. Suppl. (Stockh.) 520:59-61, 1995.

Ewald JR. Physiologische Untersuchungen uber das Endorgan des Nervus Octavus. Wiesbaden, Germany, Bergmann, 1892.

Freedman EG, Sparks DL. Activity of cells in the deeper layers of the superior colliculus of the rhesus monkey: evidence for a gaze displacement command. J. Neurophysiol. 78:1669-1690, 1997.

Gilchrist DP, Curthoys IS, Cartwright AD, Burgess AM, Topple AN, Halmagy GM. High acceleration impulsive rotations reveal severe long-term deficits of the horizontal vestibulo-ocular reflex in the guinea pig. Exp. Brain Res. 123:242-254, 1998.

Halmagy GM, Curthoys IS. A clinical sign of canal paresis. Arch. Neurol. 45:737-739, 1988.

Hashino E, Shero M, Salvi RJ. Lysosomal targeting and accumulation of aminoglycoside antibiotics in sensory hair cells. Brain Res. 777:75-85, 1997.

Harner SG, Drisco Cl, Facer GW, Beatty CW, McDonald TJ. Longterm follow-up of transtympanic gentamicin for Mõniòre's syndrome. Otol. Neurotol. 22:210-214, 2001.

Hashino E, Shero M, SAlvi RJ. Lysosomal targetting and accumulation of aminoglycoside antibiotics in sensory hair cells. Brain Res. 777:75-85, 1997.

Hirsch BE, Kamerer DB. Intratympanic gentamicin therapy for Ménière's disease. Am. J. Otol. 18:44-51, 1997.

Hoffer ME, Allen K, Kopke RD, Weisskopf P, Gottshall K, Wester D. Transtympanic versus sustained-release administration of gentamicin: kinetics, morphology, and function. Laryngoscope 111:1343-1357, 2001.

Jongkees LBW, MaAs JPM, Philipszoon AJ. Clinical nystagmography: A detailed study of electronystagmography in 341 patients with vertigo. Pract. Otorhinolaryngol. (Basel) 24:65-93, 1962.
Kaplan DM, Nedzelski JM, Chen JM, Shipp DB. Intratympanic gentamicin for the treatment of unilateral Ménière's disease. Laryngoscope 110:1298-1305, 2000.

LANGE G. Ototoxische antibiotika in der behandlung des morbus Mõniòre. Ther. Woche Wochensch. Prakt. Med. 26:1-6, 1976.

LANGE G. Gentamicin and other ototoxic antibiotics for the transtympanic treatment of Mõniòre's disease. Arch. Otorhinolaryngol. 246:269-270, 1989.

LANGE G. Transtympanic gentamycin in the treatment of Mõniòre's disease. Rev. Laryngol. Otol. Rhinol. (Bord.) 116:151-152, 1995a.

LANGE G. Twenty-seven years' experience with transtympanic aminoglycoside treatment of Ménière's disease. Laryngorhinootolgie 74:720-723, 1995b.

Lasker DM, Hullar TE, Minor LB. Horizontal vestibuloocular reflex evoked by high-acceleration rotations in the squirrel monkey. III. Responses after labyrinthectomy. J. Neurophysiol. 83:2482-2496, 2000.

Lopez I, Honrubia V, Lee S, Li G, Beykirch K. Hair cell recovery in the chinchilla crista ampullaris after gentamicin treatment: a quantitative approach. Otolaryngol. Head Neck Surg. 119:255262, 1998.

Lopez I, Honrubia V, Lee SC, Schoeman G, Beykirch K. Quantification of the process of hair cell loss and recovery after gentamicin treatment. Int. J. Dev. Neurosci. 15:447-461, 1997.

MINOR LB. Intratympanic gentamicin for control of vertigo in Ménière's disease: vestibular signs that specify completion of therapy. Am. J. Otol. 20:209-212, 1999.

Minor LB, Cremer PD, Carey JP, Della Santina CC, Streubel SO, WEG N. Symptoms and signs in superior canal dehiscence syndrome. Ann. N. Y. Acad. Sci. 942:259-273, 2001.

Minor LB, Goldberg JM. Influence of static head position on the horizontal nystagmus evoked by caloric, rotational and optokinetic stimulation in the squirrel monkey. Exp. Brain Res. 82:1-13, 1990.

Monsell EM, Balkany ta, Gates Ga, Goldenberg RA, Meyerhoff WL, House JW. Committee on Hearing and Equilibrium guidelines for the diagnosis and evaluation of therapy in Ménière's disease. Otolaryngol. Head Neck Surg. 113:181-185, 1995.

Murofushi T, Halmagy GM, Yavor RA. Intratympanic gentamicin in Ménière's disease: Results of therapy. Am. J. Otol. 18:52-57, 1997.

Nedzelski JM, Schessel DA, Bryce Ge, Pfleiderer AG. Chemical labyrinthectomy: Local application of gentamicin for the treatment of unilateral Ménière's disease. Am. J. Otol. 13:18-22, 1992.

Nedzelski JM, Chiong CM, Fradet G, Schessel DA, Bryce GE, Pfleiderer AG. Intratympanic gentamicin instillation as treatment of unilateral Ménière's disease: Update of an ongoing study. Am. J. Otol. 14:278-282, 1993.

Odkvist LM, Bergholtz LM, Lundgren A. Topical gentamycin treatment for disabling Ménière's disease. Acta Otolaryngol. Suppl. (Stockh.) 412:74-76, 1984.

PAIGE GD. Caloric responses after horizontal canal inactivation. Acta Otolaryngol. (Stockh.) 100:321-327, 1985.

Park JC, Cohen GM. Vestibular ototoxicity in the chick: effects of streptomycin on equilibrium and on ampullary dark cells. Am. J. Otolaryngol. 3:117-127, 1982.

Park JC, Cohen GM. Further observations of vestibular ototoxicity in the chick: effects of streptomycin on the ampullary sensory epithelium. Am. J. Otolaryngol. 5:387-393, 1984.

PENDER DJ. Gentamicin tympanoclysis: Effects on the vestibular secretory cells. Am. J. Otolaryngol. 6:358-367, 1985.

Proctor L, Dix R, Hughes D, Rentea R. Stimulation of the vestibular receptor by means of step temperature changes during continuous aural irrigation. Acta Otolaryngol. (Stockh.) 79:425-435, 1975. 
RaUCH SD, OAS JG. Intratympanic gentamicin for treatment of intractable Ménière's disease: A preliminary report. Laryngoscope 107:49-55, 1997.

Santos PM, Hall R, Snyder J, Hughes LF, Dobie RA. Diuretic and diet effect on Ménière's disease evaluated by the 1985 committee on hearing and equilibrium guidelines. Otolaryngol. Head Neck Surg. 109:680-689, 1993.

ScHAcht J. Biochemical basis of aminoglycoside ototoxicity. Otolaryngol. Clin. North Am. 26:845-856, 1993.

Schmid-Priscoveanu A, Bohmer A, Obzina H, Straurnann D. Caloric and search-coil head-impulse testing in patients after vestibular neuritis. J. Assoc. Res. Otolaryngol. 2:72-78, 2001.

ScHukNECHI HF. Ablation therapy in the management of Ménière's disease. Acta Otolaryngol. Suppl. (Stockh.) 132:1-4, 1957.

Silverstein H, Arruda J, Rosenberg SI, Deems D, Hester TO. Direct round window membrane application of gentamicin in the treatment of Ménière's disease. Otolaryngol. Head Neck Surg. 120:649-655, 1999.

Sobkowicz HM, August BK, SLAPNick SM. Post-traumatic survival and recovery of the auditory sensory cells in culture. Acta Otolaryngol. (Stockh.) 116:257-262, 1996.

SONG BB, Sha SH, Schacht J. Iron chelators protect from aminoglycoside-induced cochleo- and vestibulo-toxicity. Free Radic. Biol. Med. 25:189-195, 1998.

Straumann D, Zee DS, Solomon D, Lasker AG, Roberts DC. Transient torsion during and after saccades. Vis. Res. 35:3321-3334, 1995.

Tabak S, Collewjn H, Boumans LJJM, Van der Steen J. Gain and delay of human vestibulo-ocular reflexes to oscillation and steps of the head by a reactive torque helmet. I. Normal subjects. Acta Otolaryngol. (Stockh.) 117:785-795, 1997a.

Tabak S, Collewijn H, Boumans LJ, Van der Steen J. Gain and delay of human vestibulo-ocular reflexes to oscillation and steps of the head by a reactive torque helmet II. Vestibulardeficient subjects. Acta Otolaryngol. (Stockh.) 117:796-809, $1997 b$.

Tian J-R, Crane BT, Demer JL. Vestibular catch-up saccades in labyrinthine deficiency. Exp. Brain Res. 131:448-457, 2000.

Tian J-R, Shubayev I, Baloh RW, Demer JL. Impairments in the initial horizontal vestibulo-ocular reflex of older humans. Exp. Brain Res. 137:309-322, 2001.

Toth AA, PARnes LS. Intratympanic gentamicin therapy for Ménière's disease: Preliminary comparison of two regimens. J. Otolaryngol. 24:340-344, 1995.

Tsuji K, Velazquez-Villasenor L, Rauch SD, Glynn RJ, Wall C III, Merchant SN. Temporal bone studies of the human peripheral vestibular system. 4. Ménière's disease. Ann. Otol. Rhinol. Laryngol. 181:26-31, 2000.

Wanamaker HH, Slepecky NB, Cefaratti LK, Ogata Y Comparison of vestibular and cochlear ototoxicity from transtympanic streptomycin administration. Am. J. Otol. 20:457-464, 1999.

Zheng JL, Keller G, GaO WQ. Immunocytochemical and morphological evidence for intracellular self-repair as an important contributor to mammalian hair cell recovery. J. Neurosci. 19:2161-2170, 1999. 